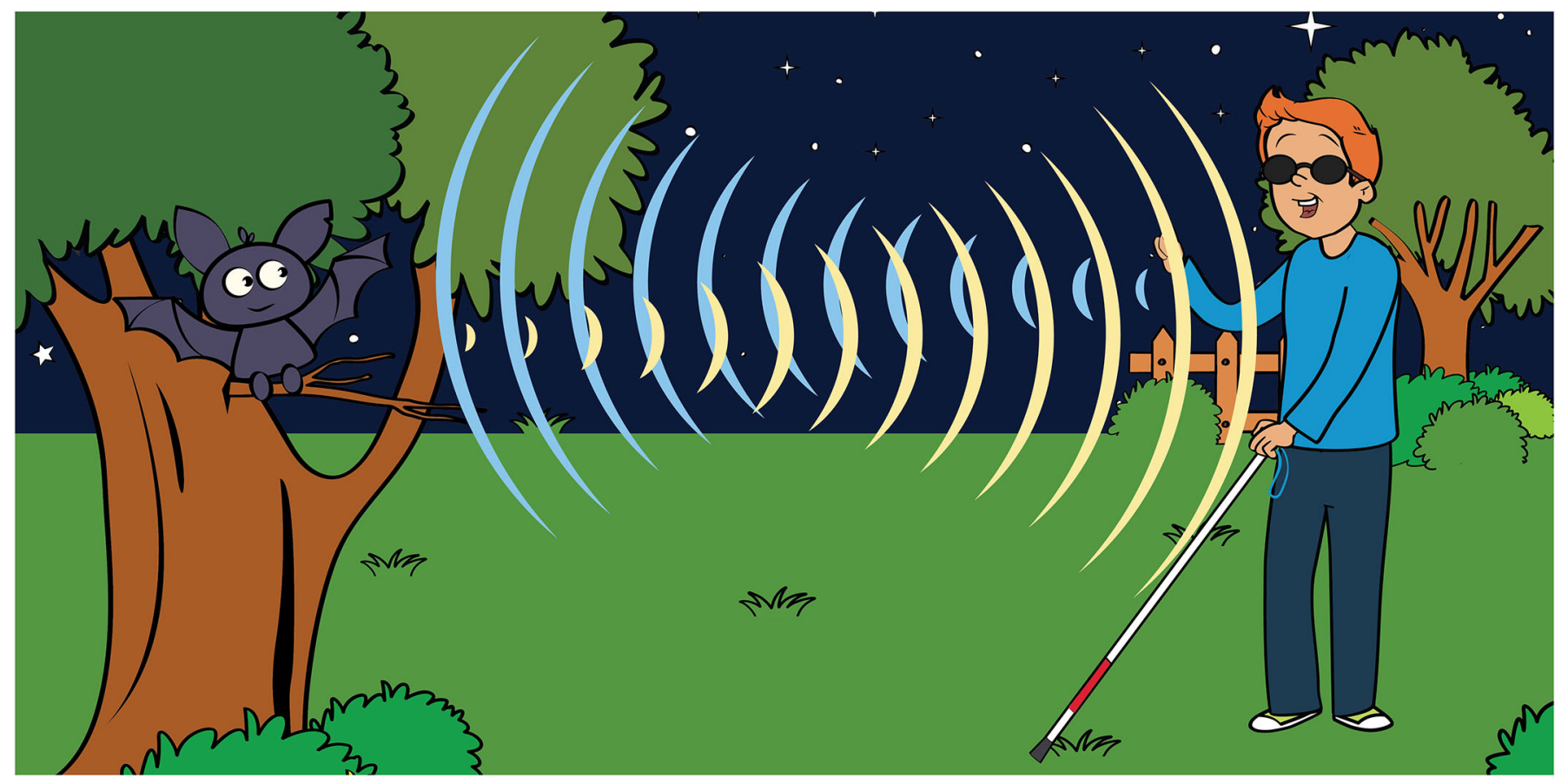

\title{
BLIND HUMANS CAN DEVELOP THE SUPERPOWER OF BATS!
}

\section{Luana da Silva Chagas ${ }^{1,2^{*}}$ and Daniel de Abreu Damasceno Júnior ${ }^{3}$}

${ }^{1}$ Neuroscience Program, Department of Neurobiology, Biology Institute, Fluminense Federal University, Niteroi, Brazil

${ }^{2}$ Neuroscience Program, Department of Neurobiology, Nucleus for Research, Education, Dissemination and Extension in Neuroscience-NuPEDEN, Biology Institute, Niteroi, Brazil

${ }^{3}$ Ecology of Mammals Lab-LEMA, Department of Ecology, Biology Institute, Rio de Janeiro State University, Rio de Janeiro, Brazil

\section{YOUNG REVIEWER:}

NINA

AGE: 15
In comic books, the superheroes have fascinating powers and abilities that help them to deal with all kinds of challenges that arise in their daily lives. Take Superman as an example. He uses his super-hearing ability to know what is going on in the city. Curiously, some of these exceptional abilities can be found where we least expect them-in animals like bats. Bats have an ability called echolocation that helps them to perceive obstacles, food, and potential dangers in the dark. Humans can also learn the superpower of echolocation. Scientists have found that some blind people can echolocate, and that they still use the vision area of the brain to understand the environment! In other words, they can "see with their ears"! Keep reading to find out what happens in the brain to allow humans to have an echolocation superpower like bats! 


\section{INTRODUCTION}

Our senses are like superpowers that help us to perceive the world, plan, decide, and react to everything we encounter. Sometimes we plan our reactions; other times, we react so quickly that we do not even think about it. This variety of responses is due to the way that the brain is organized. Vision is a precious power that allows us to interpret the world. Vision shows us a world of countless colors and shapes, rich in clues that allow us to understand our location and the orientation of our bodies, to move around obstacles safely, and to avoid danger.

The powers of comic book superheroes are often beyond human abilities. Some of them are skills that we do not have, but other animals do have, such as flying, super strength, and heightened or new senses. Have you ever wondered how Superman knows exactly where and when someone is facing danger? Superman's most important superpower is super-hearing! He can hear a cry for help, a bomb ticking, and even a runaway car, no matter how far away they are. Imagine being able to listen for sounds over great distances and know precisely where they are coming from! In real life, bats have a version of this superpower, too!

Bats are the second largest group of mammals, and the only mammals capable of flying. Bats navigate using a special ability called echolocation. They emit sounds and use the echoes that come back to locate the obstacles around them. If we could learn this ability, how would our brains readjust? How could we decide which actions to take or even detect objects in our surroundings without visual cues? Could humans and bats have more in common than one might think?

\section{TRAIN TRACKS MAPS THE BRAIN}

The brain is responsible for storing, interpreting, and organizing all the information we receive from the world through our senses. Almost

\section{NEURONS}

Brain cells that transmits electrical information between different parts of the brain.

PRIMARY VISUAL CORTEX

A brain area, located in the back of the brain, that is essential for processing visual information. immediately, this information can be transformed into a reaction, movement, or behavior. For instance, our brains can capture visual cues and move our bodies to dodge something that is coming toward us, often without us even thinking about it. How does this happen?

The retina, a layer at the back of our eyeballs that is sensitive to light, captures visual information from the environment and transforms it into electrical activity. This electrical activity passes along cells called neurons, to the brain. You can imagine the brain as a large train network. The passengers are the electrical energy from the retina that will travel along tracks made of neurons, past various train stations-areas of the brain where different levels of processing take place. The last stop for visual information is a part of the brain called the primary visual cortex, which allows us to become conscious of what 
Figure 1

The brain can be imagined as a train network, in which information from the environment is processed to create specific "maps" in the brain for the information from our various senses to follow.

\section{TOPOGRAPHIC} MAPS

The brain's precise organization where neurons target specific brain regions to construct the brain maps.

\section{VOCALIZATION}

The sound produced by an animal with its mouth.

\section{$\mathrm{ECHO}$}

The reflection of the sound after hitting an obstacle.

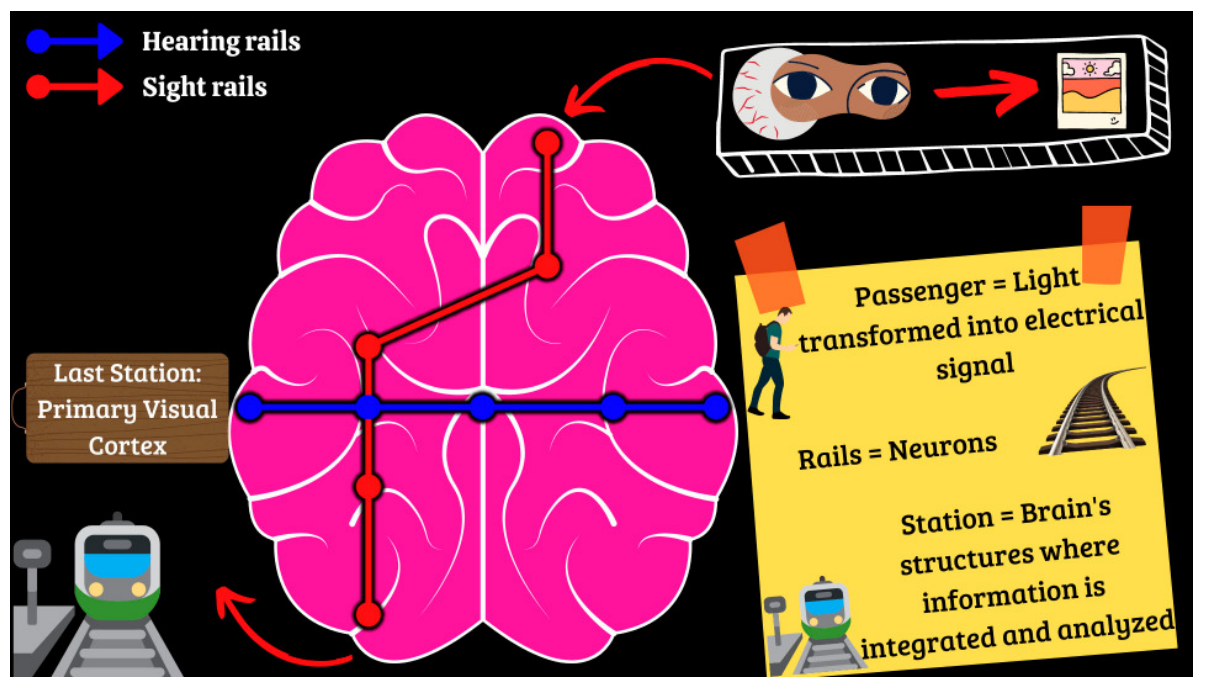

Figure 1

we are seeing. Each of our senses has its own rail lines and stations in the brain. Occasionally, these lines intersect, and the interactions between our senses and our memories can complement the visual information taken in through our eyes (Figure 1).

The human brain has a very particular organization: the train rails are very precise, so that they tightly regulate the transport of information through the proper brain stations on the way to its final stop. This organization is called topographic maps. This is like each passenger on a specific train needing a train ticket with a predetermined destination, so no one can mistakenly go to the wrong place. The brain is organized this way so that information from the senses does not get mixed up and can be extremely specific and detailed. For example, the proper flow of electrical activity through the different stations in the brain enables us to see colors, borders, perspectives, and depths, and to perceive shapes and movement extremely precisely.

\section{ECHOLOCATION: THE SUPERPOWER OF BATS}

About 200 years ago, a researcher named Lazaro Spallanzani was the first to study echolocation in bats. He noticed that, even in the total absence of light, bats never collided with obstacles [1]. Today we know that bats, dolphins, and whales use echolocation. These animals can emit sounds at frequencies that are either higher (bats) or lower (dolphins and whales) that those humans can hear. These sounds travel through the environment and, when they encounter obstacles, they bounce off and return to the animals' ears, to help them to understand the surrounding environment. The sounds emitted by these animals are called vocalizations and the sounds that returns are called the echoes. 
Figure 2

How does

echolocation work?

Bats can emit sounds at

high frequencies that

humans cannot hear.

These sounds travel

through the air until

they collide with an

obstacle. The sounds

bounce off the obstacle

and come back to the

bats' ears, to help them

navigate. If the sound

bounces off a tree, the

bat just swerves around

it. If the sound bounces

off a bug or any other

type of food, bats can

move toward it.

\section{GEOMETRIC}

PROPAGATION

The distance that a sound travels in space.

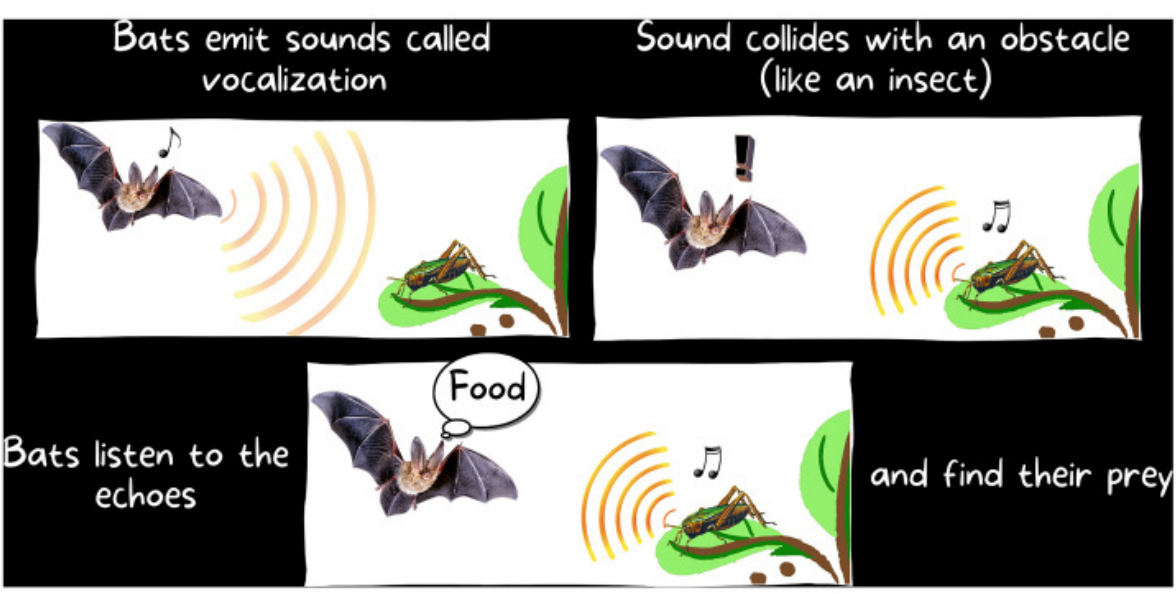

Figure 2

Sound behaves differently in environments with different obstacles. One characteristic of sound that changes according to the environment is called geometric propagation. Geometric propagation refers to the distance over which the sound spreads out. The farther away the sound travels through the air, the weaker it becomes. Objects also absorb and reflect sound differently. For instance, if you knock on a wooden door and then on a metal one, you can notice that the sound is different. Imagine being able to tell apart the echoes that bounce off a tree, a fly, or even a bird! That is exactly what bats can do! They vocalize so that, upon hearing the echo, they know exactly what is ahead. They can determine how far away objects are, as well the height and size of objects (Figure 2).

Echolocation is an important tool that helps bats navigate around obstacles, communicate, and find food [2]. Bats have had this skill for millions of years and they have developed structures, like large ears, that help them to interpret the echoes. Each bat species vocalizes at a different rate, intonation, and frequency and it is related to the type of food they eat. There are bats that feed on fruits, insects, nectar, fish, and blood, as well as small vertebrates such as mice and lizards. But what about humans? Can humans use echolocation?

\section{BLIND HUMANS USE ECHOLOCATION!}

Studies have reported that blind humans can use echolocation to avoid obstacles. According to one study, two blind people who lost their sight at a young age learned to detect surrounding objects using mouth-clicks as echolocators! The scientists measured the brain function of these individuals while they were echolocating objects in front of them. The scientists compared the results of the two blind people to results from two people with normal vision. The scientists found that the two blind participants showed higher brain activity within the brain's visual cortex when compared to sighted participants 
Figure 3

In blind people, the "rails" in the brain are reorganized, so that sound signals can travel along vision rails, to the primary visual cortex. This rearrangement of neurons allows blind people to use echolocation to identify the distance, size, and location of objects ahead. This ability is due to the brain map reorganization that allows sounds to build vision rails.

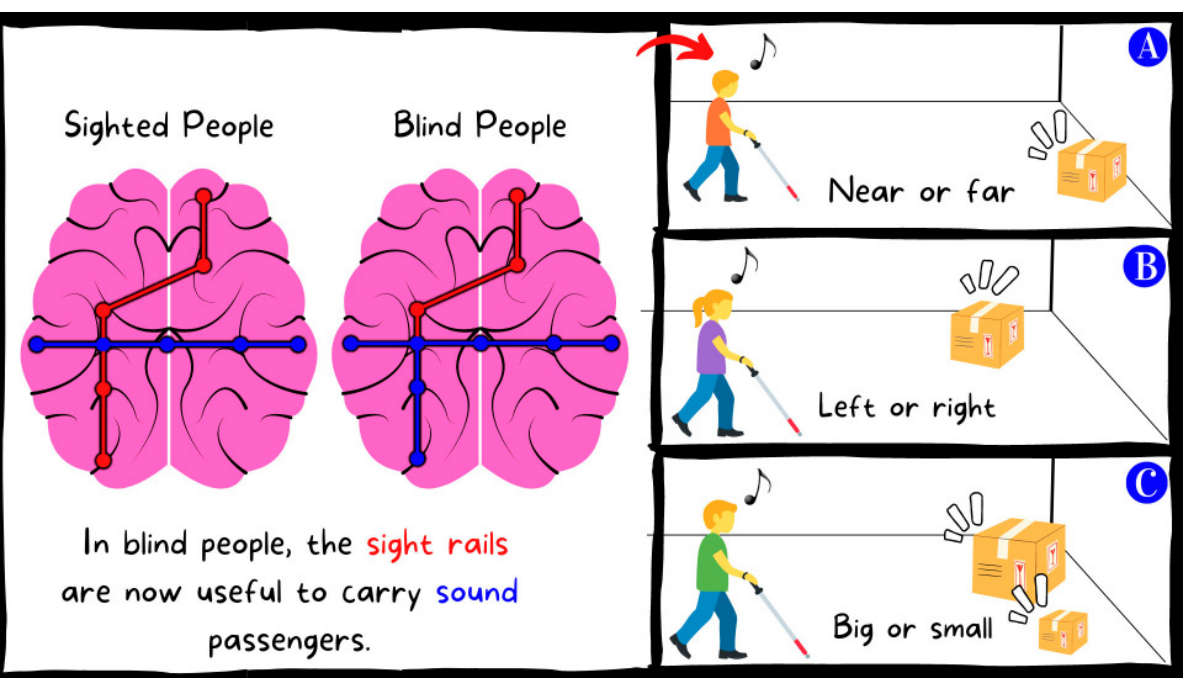

Figure 3

while they were hearing echoes and locating the objects. However, no differences in brain activity were observed within the auditory (hearing) areas of the brain between sighted and blind participants [3].

Noises such as mouth clicks, talking, whistling, humming, footsteps, or a tapping cane allow blind people to use echolocation and detect objects with a distance accuracy of $40 \mathrm{~cm}$. They can notice angle changes of $4^{\circ}$ or more. So, people who can echolocate can detect if an object is moved closer, farther away, to the left or to the right. They can also pinpoint targets and tell the difference between objects of different sizes (Figure 3) [3]!

\section{BLINDNESS CHANGES THE "MAPS" IN THE BRAIN}

Throughout life, people with normal sight build special maps in their brains, specifically to the primary visual cortex. This means that the neurons are connected in ways that map out a particular direction for the electrical signals generated from light to travel. Likewise, by using our hearing, we also build specific maps in our brains, to bring sound information to another region called the primary auditory cortex. Previously, scientists thought these neural maps could only be formed when we put those specific senses to use. However, in the absence of one sense, such as happens in blindness, those brain maps remodel themselves so that the brain can adapt. This process of remodeling the neuronal pathways in the brain is known as neuroplasticity. For example, blind people who have the incredible ability to echolocate use sound to build a brain map for vision. Think of this like the hearing rail network building new tracks to reach the primary visual cortex-the final station on the vision rail line! As a result, this newly created brain rail line can make a "picture" of the surrounding space by using the echoes of emitted sounds. Scientists found that the visual map 
constructed in blind individuals using sound is very similar to the visual maps that are formed from visual information in people with normal sight. The greater a blind person's ability to echolocate, the greater the similarity of their visual map to that of sighted individuals [4].

\section{CONCLUSION}

Scientific research on bats has brought many improvements to our everyday lives, from medicines that stop blood from clotting to the discovery of sonars These discoveries highlight the importance of preserving and protecting bats and their habitats. The study of bats' echolocation superpower has helped to improve the lives of blind people, and it has also contributed to our understanding of the changes that happen in the brain when the sense of vision is not available. The remodeling of the neural tracks in the brain starts to happen shortly after blind people lose their sight, when they start using sound to navigate their environments. In fact, echolocation can even be learned by people who can see. All we need is some practice and attention, and we can remodel the tracks in our brains, too!

\section{ACKNOWLEDGMENTS}

We would like to acknowledge MSc. Elenn Ferreira for the valuable english revision on an earlier draft of this manuscript.

\section{REFERENCES}

1. Thaler, L., and Goodale, M. A. 2016. Echolocation in humans: an overview. WIREs Cogn. Sci. 7:382-93. doi: 10.1002/wcs.1408

2. Giannini, N., and Kalko, E. K. V. 2005. The guild structure of animalivorous leaf-nosed bats of Barro Colorado Island, Panama, revisited. Acta Chiropterol. 7:131-46. doi: 10.3161/1733-5329(2005)7[131:TGSOAL]2.0.CO;2

3. Thaler, L., Arnott, S. R., and Goodale, M. A. 2011. Neural correlates of natural human echolocation in early and late blind echolocation experts. PLOS ONE. 6:e20162. doi: 10.1371/journal.pone.0020162

4. Norman, L., and Thaler, L. 2019. Retinotopic-like maps of spatial sound in primary 'visual' cortex of blind human echolocators. Proc. R. Soc. B Biol. Sci. 286:20191910. doi: 10.1098/rspb.2019.1910

SUBMITTED: 11 November 2020; ACCEPTED: 07 February 2022; PUBLISHED ONLINE: 03 March 2022.

EDITOR: Julia W. Y. Kam, University of Calgary, Canada

SCIENCE MENTOR: Analía Arévalo 
CITATION: da Silva Chagas L and de Abreu Damasceno Júnior D (2022) Blind Humans Can Develop the Superpower of Bats! Front. Young Minds 10:628440. doi: $10.3389 /$ frym.2022.628440

CONFLICT OF INTEREST: The authors declare that the research was conducted in the absence of any commercial or financial relationships that could be construed as a potential conflict of interest.

COPYRIGHT @) 2022 da Silva Chagas and de Abreu Damasceno Júnior. This is an open-access article distributed under the terms of the Creative Commons Attribution License (CC BY). The use, distribution or reproduction in other forums is permitted, provided the original author(s) and the copyright owner(s) are credited and that the original publication in this journal is cited, in accordance with accepted academic practice. No use, distribution or reproduction is permitted which does not comply with these terms.

\section{YOUNG REVIEWER}

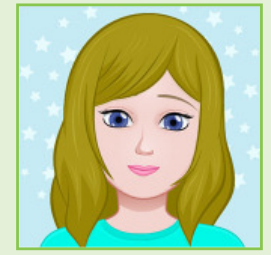

\section{NINA, AGE: 15}

My name is Nina and I like to draw, make origami and cook with my family. I am always looking to learn new things. At school I like to hang out with friends, and my favorite subjects are art, P.E. and Portuguese, because I like writing stories.

\section{AUTHORS}

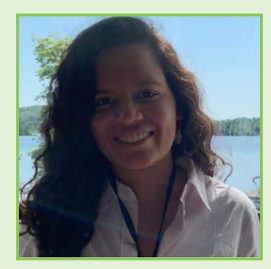

\section{LUANA DA SILVA CHAGAS}

I am a postdoc researcher in the Neural Plasticity Lab at Federal Fluminense University, Brazil. I am interested in understanding how some environmental factors could change the way neurons are connected in the brain, in the early phases of development. I also investigate how damage to the brain can trigger immune activity and influence neuroplasticity. I also work with scientific communication, spreading the message about how important neuroscience can be in our everyday lives. *luana_chagas@id.uff.br

\section{DANIEL DE ABREU DAMASCENO JÚNIOR}

I am an ecologist in the Ecology of Mammals Lab, at Rio de Janeiro State University, Brazil. I do research on the biology of bats and their relationship with the environment. I investigate how bats may be used to help us know if a place is safe or harmful for humans to live in. In addition, I communicate scientific knowledge to improve public perception of bats, by talking about the importance of these animals to the environment and to humans. 